\title{
Changes in Conflict Resolution Style over Time: The Risk for Persons with Alzheimer's Dementia
}

\author{
VandeWeerd C ${ }^{1^{*}}$, Paveza G ${ }^{2}$, Estefan, L. ${ }^{1}$ and Corvin, J. ${ }^{3}$ \\ ${ }^{1}$ The Harrell Center for the Study of Family Violence, Department of Community and Family Health, College of Public Health, University of South Florida, Tampa, Florida, \\ USA \\ ${ }^{2}$ School of Health and Human Services, Southern Connecticut State University, New Haven, United States \\ ${ }^{3}$ The Department of Global Health, College of Public Health, University of South Florida, Tampa, Florida, USA \\ *Corresponding author: Carla VandeWeerd, Assistant Professor and Associate Director, The Harrell Center for the Study of Family Violence, Department of \\ Community and Family Health, College of Public Health, University of South Florida, 13301 Bruce B. Downs Blvd, MDC, 56, Tampa, Florida, USA 33612, Tel: \\ 813-974-7773; E-mail: cvandewe@health.usf.edu
}

Rec date: June 17, 2014, Acc date: August 26, 2014, Pub date: September 05, 2014

Copyright: (c) 2014 C. VandeWeerd, et al. This is an open-access article distributed under the terms of the Creative Commons Attribution License, which permits unrestricted use, distribution, and reproduction in any medium, provided the original author and source are credited.

\begin{abstract}
Background: Elder mistreatment is a serious issue affecting between 300,000 and 800,000 older adults. Elder mistreatment has serious consequences for older adults and can include immunological dysfunction, increased mortality and emotional difficulties such as depression, feelings of inadequacy and self-contempt. Sub-groups such as persons with Alzheimer's disease have heightened risk for elder mistreatment, but it is not clear whether this heightened risk represents life-long patterns of abuse between persons or whether they represent a change in conflict style over time as a result of changes associated with dementia.
\end{abstract}

Methods: Data analyzed in this study were collected as part of the Aggression and Violence in Community Based Alzheimer's Study [AV-CAD] and represents patient caregiver/dyads who received care at one of five state funded medical clinics or who belonged to one of three local chapters of the Alzheimer's Association. Data were collected via in-person interview and mailed survey, and changes in conflict resolution style (reasoning, verbal aggression and violence) pre and post dementia were measured using the Conflict Tactic Scale (CTS) and analyzed using McNemar's Test.

Results: Reasoning was used as a conflict resolution style in $91.4 \%$ of caregivers and $89.3 \%$ of elders prior to the onset of dementia and in $66.3 \%$ of caregivers and $45.3 \%$ of elders in the past year (post dementia diagnosis). Reasoning in the post dementia period was significantly related to use of reasoning in the pre dementia period for caregivers $(X 2=7.47, p=.0032)$ and approached significance for elders $(X 2=6.00 ; p=.057)$. Use of verbal aggression (VA) and violence (V) as a conflict resolution style post dementia was higher for both caregivers (VA: 59.3\%; V: $16.8 \%$ ) and elders (VA: $68.7 \%$; V: $24 \%$ ), but was not significantly related to behaviors in the pre-dementia period for caregivers $(V: X 2=1.55, p=.536$; VA: $X 2=0.67, p=.528)$ or elders $(V: X 2=0.54, p=.628 ; V A: X 2=0.43, p=.621)$.

Conclusions: This study lends support to the idea that elder abuse in a large number of persons with Alzheimer's disease may be in part a result of the etiology of the disease and is susceptible over time. Implications for policy, practice and future research are discussed.

Keywords: Aging; Elder Mistreatment; Abuse; Caregiving

\section{Abbreviations:}

AD: Alzheimer's disease; AV_CAD: Aggression and Violence in Community Based Alzheimer's Families Grant; CTS: Conflict Tactic Scale; MMSE: Mini Mental Status Examination

\section{Background}

Elder mistreatment is a serious issue affecting between 300,000 and 800,000 older adults [1]. It includes categories such as physical abuse, which includes any acts of violence that may result in pain, injury, impairment or disease [2], psychological or verbal mistreatment, which refers to the use of verbal assaults, insults, threats, intimidation, humiliation, and harassment, or any treatment that results in emotional or mental anguish to the recipient, and neglect, "the failure of responsible party(ies) to act so as to provide, or to provide what is prudently deemed adequate and reasonable assistance that is available and warranted to ensure that the older adult's basic physical, psychological, social and financial needs are met, resulting in harmful effects for the older adult" [3]. Elder mistreatment has been linked to health problems such as immunological dysfunction [4-9], and increased mortality $[10,11]$. It results in emotional difficulties such as decreased self-esteem [4,8,12-14], depression [7,9,15-17] feelings of inadequacy, and self-contempt $[13,14]$. It has been shown to result in family distress, impaired life functioning [9], and cognitive difficulties [4]. Factors such as abuse history [18,19], age and gender of perpetrators [20-23], pathology of the perpetrator [24-26] dependence [27-29], social isolation [17,18,30-33], depression [25,34-38], and caregiver emotional problems $[25,26,37,39,40]$ have been postulated to be related to mistreatment. In addition, cognitive impairment has been 
identified as a unique risk factor that may increase risk for mistreatment in older persons $[1,33,38,41,42]$.

It is estimated that as many as 4 million individuals are suffering from moderate to severe dementia [43]. Abuse of dementia patients by family caregivers is reported to be common $[21,41,42,44,45]$ and prior aggression in the dementia patient, premorbid relationship between the patient and caregiver, and frequent behavioral problems have been linked to aggression and violent behavior $[21,41,42,44,45]$. Steinmetz (1988) was one of the first to suggest that abuse may be interactive, that is, related to the patient's verbal and physical abuse of the caregiver, and this idea has received support from other researchers [46]. Paveza et al. found a dyadic relationship between patient and caregiver physical violence in their study on Alzheimer's Disease (AD) patients in the PACT registry [42] as did Coyne et al. [21] and Paveza et al. [21,38]. In both of these studies physical abuse on the part of demented persons receiving care was related to physically abusive behaviors on the part of caregivers. What is not known as yet is whether these relationships represent a life-long pattern of abuse between persons or whether they represent a change in conflict resolution strategy over time as a result of changes associated with dementia. This study will examine this question by looking at change in conflict resolution strategy in persons caring for a community dwelling older adult with Alzheimer's disease in the state of Florida in the period prior to the onset of dementia symptoms and in the period after the onset of symptoms.

\section{Methods}

\section{The Data Set}

Data analyzed here were collected as part of the Aggression and Violence in Community Based Alzheimer's families grant (AV_CAD), and potential subjects were enrolled though solicitation via membership in one of three local chapters of the Alzheimer's Association located in Tampa, Orlando, and Miami, or though their participation with the five state funded memory disorder clinics (Tampa, Central Florida, North Broward, Miami, and Miami Beach) over a three step procedure (Figure 1) and are detailed in VandeWeerd and Paveza [38].

- Step One:

Mass mailing of introductory pamphlet to all persons who were members of a Florida State Alzheimer's Association $(n=5,648)$ or who were members of a state-funded memory disorder clinic (MDC) diagnosed with $\mathrm{AD}(\mathrm{n}=1,781)$ during study enrollment.

- Step Two:

Telephone interview to ensure interested subjects $(\mathrm{n}=1011)$ met eligibility criteria, confirm address for the mailing of questionnaire and scheduling of in-home interview. Of the interested subjects, $65 \%$

$(n=657)$ met inclusion criteria, and 254 agreed to participate once the study was explained in detail.

- Step Three:

In-home interview conducted with Caregivers $(\mathrm{n}=254)$ and Patients where cognitively eligible $(n=60)$, or who had a surrogate available to provide responses on their behalf $(\mathrm{n}=16)$

\section{Figure 1: Data Collection}

In step one, all older adults diagnosed with $\mathrm{AD}$ who were receiving treatment at one of the memory disorder clinics $(n=1,781)$, or who were members of Alzheimer's Associations during the study enrollment period $(n=5,648)$ were mailed an introductory pamphlet explaining the study. Pamphlet packages included a response card indicating a caregiver or elders interest in the study and their consent to have their information released from their enrollment site to the study team. In step two, all interested persons $(n=1011)$ were contacted by the University of South Florida (USF) study team who verified whether the elder and caregiver met the inclusion criteria, and explained the study in detail. If subjects met inclusion criteria and were interested in participating, address information for mailing the in-home questionnaire was collected and an appointment for in-home interview was scheduled. In step three of the study, in-home interviews were completed with caregivers and elders where eligible, using a computer assisted live interview technique.

Inclusion criteria for the study required that: 1) elders be 60 years of age or older, 2) have a diagnosis of $\mathrm{AD}$ either according to the NINCDS/ADRDA criteria or dementia of Alzheimer's type according to the DSM-III-R or DSM-IV in the 3 years prior to their enrollment in the study, 3) possess the ability to speak English, and 4) achieve a score of 16 or greater on the Folstein Mini Mental Status Exam (MMSE.) Inclusion criteria for caregivers required that: 1) caregivers be a family member, 2) possess the ability to speak English, and 3) provide 20 hours a week or more of care, and possess a telephone.

Families who did not meet the inclusion criteria were excluded from participating in the study with the exception of families who met all criteria except that the elder did not meet the requisite MMSE score. In these cases a surrogate could be used on the part of the elder to provide answers on the elder's behalf providing that the surrogate felt close to the patient, had met at least 1 time per week with the patient over the past year, and was not the primary caregiver.

Data collection was limited to an eligible MMSE score of 16 and to persons diagnosed within the 3 -year period prior to enrollment to reduce the number of patients who were likely to have surpassed the cognitive decline cut-off. This time limit was also an effort to decrease the response bias that a large number of surrogates might induce. Of the 76 elders who participated, only 17 required the inclusion of surrogate information. This research was conducted under the supervision of the USF Internal Review Board and in compliance with the Helsinki Declaration (http://www.wma.net/en/30publications/ 10policies/b3/).

\section{Tests and Measures}

The Conflict Tactic Scale (CTS) was the principal measure of elder mistreatment in the AV_CAD, and the reasoning, verbal aggression, and violence sub-scales served as the principal outcome measure of this study. The CTS was originally developed by Straus and his colleges for use in their seminal study on violence in the American family [47]. This instrument was chosen because of its frequency of use in the study of violence in families [47-49], as well as by studies that have looked at violence in $\mathrm{AD}$ families on a smaller scale [42]. It includes items in compliance with definitions for verbal and physical mistreatment such as "insulted or swore at the other one", "pushed, shoved, or grabbed", "slapped, and spanked", and for reasoning such as, "discuss the issue calmly" and "got information to back up side of things" as measured through caregivers' reports of their own behavior and caregivers' reports of elders' behavior. It offers a dichotomous way to measure the presence or absence of mistreatment and has a strong internal consistency with coefficient alphas of 0.82 and greater for the sub-scales. For each question that comprises the CTS, subjects were asked to provide responses across three time periods: did it ever happen? Did it happen prior to symptoms? And did it happen in the 
past year? Information from each period was used to generate a subscale score for the presence or absence of the use of each resolution strategy (reasoning, verbal aggression, and violence) at that time. Data over the last two time periods (the period prior to symptoms, and in the past year) serve as the focus of this paper. The period "in the past year" was used as an indicator of post dementia change as a diagnosis of $\mathrm{AD}$ was required for participation in the study.

\section{Data Analysis}

Data for the AV_CAD were collected through mailed questionnaire and in-home interview. Data collected during the in-home interview were entered immediately into an Epi-Info database format via laptop computer, and later transformed into an SPSS useable format using Stat Transfer 6.0 software. Data collected via mailed questionnaire were entered directly into an SPSS database for data analysis. Data for the CTS were collected as part of the in-home interview process. Data for this analysis were cut from the larger AV_CAD study and focused on demographics as well as reasoning, verbal aggression and violence sub-scales of the conflict tactics scale as described in tests and measures.

Demographics of the overall sample were computed and Mcnemar's test was used to compare conflict resolution strategies used in the period prior to symptoms and in the year prior to study participation. McNemar's test was chosen due to its utility of use with dichotomous variables and the presence of mistreatment within the small sample size.

\section{Results}

In all, 254 caregivers (Table 1) and 76 elders (Table 2) participated in the study. Caregivers had a mean age of 63.84 years (+13.07 years) and were primarily wives $(34.2 \%)$ and children (32\%), followed by husbands (18.5\%).

Fifty-nine percent of care-recipients were female, with a mean age of 78.57 years (+8.41 years). Both care-recipients and caregivers were 85\% Caucasian, 9.4\% Hispanic, and 4.5\% African American. Twentysix percent of caregivers and $30.6 \%$ of elders were Roman Catholics. An additional $44 \%$ of caregivers were non Roman Catholic Christians, as were $43.2 \%$ of elders. Sixty-eight percent of care-recipients lived with their caregiver. Of those, $18.6 \%$ had household incomes between $\$ 20,000$ and $\$ 29,000$.

For care-recipients who do not live with their caregivers, many are living at or near poverty. Thirty-five percent have incomes less than $\$ 20,000$ a year. Forty-nine percent of caregivers were providing care to someone with 11-15 dementia symptoms, $84.3 \%$ reported a subjective feeling that providing care to the elder was a burden, and $41.9 \%$ were seriously considering the need for nursing home placement in the future.

Table 3 illustrates conflict resolution style in the pre and post dementia periods. Reasoning in the post dementia period was significantly related to the use of reasoning as a conflict resolution style in the pre dementia period in caregivers ( $\mathrm{X} 2=7.37, \mathrm{p}=0.031$ ). Reasoning was used by $91.4 \%$ of caregivers and $89.3 \%$ of elders with $\mathrm{AD}$ prior to the onset of dementia symptoms, and by $66.3 \%$ of caregivers and $45.3 \%$ of elders in the past year. Reasoning in elders with $\mathrm{AD}$ in the pre and post dementia period approached significance $(\mathrm{X} 2=5.90, \mathrm{p}=0.055)$.
The use of verbal aggression and violence as a conflict resolution style in the period prior to dementia was not significantly associated with the use of verbal aggression in the post dementia period. Verbal aggression was used by $9.6 \%$ of caregivers as a conflict resolution strategy prior to symptoms and by $59.3 \%$ in the year period prior to enrollment in the study (X2=1.48, $\mathrm{p}=.532)$.

Verbal aggression as a conflict resolution strategy was used by $11 \%$ of elders with $\mathrm{AD}$ prior to the onset of dementia symptoms and by $68.7 \%$ in the year prior to enrollment $(\mathrm{X} 2=0.56, \mathrm{p}=.617)$.

\begin{tabular}{|c|c|c|c|}
\hline Variable & $\%$ & Variable & $\%$ \\
\hline Gender & & $\begin{array}{l}\text { Relationship to } \\
\text { Patient }\end{array}$ & \\
\hline Female & $74.80 \%$ & Wife & $34.20 \%$ \\
\hline Male & $25.20 \%$ & Husband & $18.50 \%$ \\
\hline $\begin{array}{l}\text { Mean age in years } \\
\text { (aSD) }\end{array}$ & $\begin{array}{l}63.84 \\
(+13.07)\end{array}$ & Child & $38.30 \%$ \\
\hline Age by Group & & Other & $14.00 \%$ \\
\hline $21-30$ & $0.50 \%$ & blancome & \\
\hline $31-40$ & $5 \%$ & Under $\$ 19,999$ & $10.90 \%$ \\
\hline $41-50$ & $9.90 \%$ & $\$ 20,000-\$ 29,999$ & $18.60 \%$ \\
\hline $51-60$ & $27 \%$ & $\$ 30,000-\$ 39,999$ & $13 \%$ \\
\hline $61-70$ & $19.80 \%$ & $\$ 40,000-\$ 49,999$ & $12.30 \%$ \\
\hline $71-80$ & $28.80 \%$ & $\$ 50,000+$ & $45.00 \%$ \\
\hline $81-90$ & $8.60 \%$ & Level of Depression & \\
\hline $90+$ & $0.50 \%$ & Non-Depressed & $17.40 \%$ \\
\hline Race & & Mildly depressed & $25.70 \%$ \\
\hline Caucasian & $85.10 \%$ & Moderately depressed & $36.70 \%$ \\
\hline African American & $4.60 \%$ & Severely depressed & $20.20 \%$ \\
\hline Hispanic & $10.30 \%$ & Level of Self Esteem & \\
\hline Religion & & Moderately low & $0.90 \%$ \\
\hline Roman Catholic & $26.10 \%$ & Low & $6.00 \%$ \\
\hline Other Christian & $44.10 \%$ & High & $18.10 \%$ \\
\hline Jewish & $15.80 \%$ & Moderately high & $30.20 \%$ \\
\hline Other & $14.00 \%$ & Very high & $44.70 \%$ \\
\hline
\end{tabular}

Table 1: Caregiver Demographics $(\mathrm{N}=254)$.

The use of violence as a conflict resolution strategy showed a substantial increase in the pre and post dementia periods in both elders and caregivers but was not significantly associated with the use of violence in the pre dementia period. Only three percent of caregivers and elders used violence as a resolution strategy prior to the onset of dementia symptoms and $16.8 \%$ of caregivers (X2=0.69, $\mathrm{p}=$. $521)$ and $24.2 \%(\mathrm{X} 2=0.43, \mathrm{p}=.623)$ of elders did so in the year prior to study enrollment. 
Page 4 of 7

\section{Discussion}

This study lends support to the idea that elder abuse in a large number of persons with Alzheimer's disease may be in part a result of the etiology of the disease and is susceptible to change over time.

\begin{tabular}{|c|c|}
\hline Variable & $\%$ \\
\hline \multicolumn{2}{|l|}{ Gender } \\
\hline Female & $59.00 \%$ \\
\hline Male & $41.00 \%$ \\
\hline Mean age in years (aSD) & $78.57(+8.41)$ \\
\hline \multicolumn{2}{|l|}{ Age by Group } \\
\hline $60-70$ & $14.50 \%$ \\
\hline $71-80$ & $43.40 \%$ \\
\hline $81-90$ & $36.70 \%$ \\
\hline $90+$ & $5.40 \%$ \\
\hline \multicolumn{2}{|l|}{ Race } \\
\hline Caucasian & $84.80 \%$ \\
\hline African American & $4.50 \%$ \\
\hline Hispanic & $9.40 \%$ \\
\hline Other & $1.30 \%$ \\
\hline \multicolumn{2}{|l|}{ Religion } \\
\hline Roman Catholic & $26.10 \%$ \\
\hline Other Christian & $43.10 \%$ \\
\hline Jewish & $15.80 \%$ \\
\hline Other & $14.90 \%$ \\
\hline \multicolumn{2}{|l|}{ bIncome } \\
\hline Under $\$ 19,999$ & $35.50 \%$ \\
\hline$\$ 20,000-\$ 29,999$ & $15.70 \%$ \\
\hline$\$ 30,000-\$ 39,999$ & $11.40 \%$ \\
\hline$\$ 40,000-\$ 49,999$ & $8.50 \%$ \\
\hline$\$ 50,000+$ & $28.90 \%$ \\
\hline \multicolumn{2}{|l|}{ Income } \\
\hline Under $\$ 19,999$ & $15.20 \%$ \\
\hline$\$ 20,000-\$ 29,999$ & $21.70 \%$ \\
\hline$\$ 30,000-\$ 39,999$ & $11.60 \%$ \\
\hline$\$ 40,000-\$ 49,999$ & $13.80 \%$ \\
\hline$\$ 50,000+$ & $37.60 \%$ \\
\hline \multicolumn{2}{|l|}{ Dementia Symptoms } \\
\hline 1-5 Symptoms Noticed & $1.30 \%$ \\
\hline
\end{tabular}

\begin{tabular}{|l|l|}
\hline $6-10$ Symptoms Noticed & $24.10 \%$ \\
\hline $11-15$ Symptoms Noticed & $49.10 \%$ \\
\hline $16-20$ Symptoms Noticed & $25.40 \%$ \\
\hline Level of Depression & \\
\hline No depression & $25.90 \%$ \\
\hline Minor depression & $29.60 \%$ \\
\hline Possible major depression & $16.20 \%$ \\
\hline Probable major depression & $19.90 \%$ \\
\hline Definite major depression & $8.30 \%$ \\
\hline
\end{tabular}

arepresents standard deviation; brepresents household income when not living with caregiver $(n=32)$; ${ }^{C}$ represents household income when not living with caregiver $(n=224)$

Table 2: Elder Demographics ( $\mathrm{N}=76)$.

As the data illustrate there are significant increases in the use of verbal aggression and violent conflict resolution strategies used by both patients and caregivers in the period after diagnosis, when these strategies were not used prior to the onset of dementia symptoms. It is interesting to note that at least initially caregivers endeavor to use reasoning as a conflict resolution strategy in the same way they did prior to the onset of dementia. However, as dementia progresses, verbal aggression and violent behaviors escalate on the part of the patient, whilst the ability to reason in a constructive way declines, caregivers begin to use both verbal aggression and violence as well. These data lend definitive support to the hypothesis of other researchers that aggression and violence on the part of persons caring for someone with dementia may be the result of reciprocal violence rather than stem from malevolent intent $[21,42,46]$ and suggest that services and education, rather than punishment are warranted.

Secondary symptoms of dementia such as aggression, violence, and combativeness are particularly difficult for caregivers to cope with and manage [21] but may be amenable to treatment. If the large percentage of abuse seen in this population is a behavioral outcome involving either retaliation or frustration as is suggested, in order to break the cycle it is imperative to teach caregivers techniques for distracting or reassuring patients, or for diverting their attention away from a potentially abusive situation. Feil [50], and Bell and Troxel [51] have provided excellent guides on techniques for doing these things with persons with dementia. They include suggestions for better communication such as reducing background noise while talking, and the importance of tone of voice. They also include sections on easy activities for redirecting attention from potentially hostile triggers that may result in abusive events such as blowing up a balloon and playing with it. Additionally, these manuals highlight the importance of reframing the experience, learning to recognize triggers in advance, focusing on the positives of today's capabilities, and being the memory keeper, while stressing the importance of patient dignity. Additionally, pharmacological treatment, supportive psychotherapy, education groups, and services that decrease the hours per day spent providing care (respite) would possibly provide effective solutions to decreasing behavioral outbursts on the part of patients, and increasing reasoning as a strategy on the part of caregivers [52,53]. It is important to note that reasoning still remains high among caregivers in the post dementia period indicating that caregivers maintain the desire to 
reason. Further, it suggests that an effort is still made to utilize this technique, but when this technique fails to offer any resolution, or when they are confronted with verbal and physical aggression they respond in kind.

\begin{tabular}{|l|l|l|l|l|}
\hline $\begin{array}{l}\text { Conflict Resolution } \\
\text { Style }\end{array}$ & $\begin{array}{l}\text { In the Period } \\
\text { Prior to } \\
\text { Symptoms }\end{array}$ & $\begin{array}{l}\text { In the Past } \\
\text { Year }\end{array}$ & $\mathbf{X}^{2}$ & aSignificance \\
\hline bUse of Reasoning: & & & & \\
\hline Caregivers & $91.40 \%$ & $66.30 \%$ & 7.37 & 0.031 \\
\hline Patients & $89.30 \%$ & $45.30 \%$ & 5.9 & 0.055 \\
\hline $\begin{array}{l}\text { CUse of Verbal } \\
\text { Aggression: }\end{array}$ & & & & \\
\hline Caregivers & $9.60 \%$ & $59.30 \%$ & 1.48 & 0.532 \\
\hline Patients & $11.00 \%$ & $68.70 \%$ & 0.56 & 0.617 \\
\hline dUse of Violence: & & & & \\
\hline Caregivers & $2.60 \%$ & $16.80 \%$ & 0.69 & 0.521 \\
\hline Patients & $3.10 \%$ & $24.20 \%$ & 0.43 & 0.623 \\
\hline
\end{tabular}

aMcNemar's test for significance; bas measured by the Reasoning sub-scale of the CTS; cas measured by the Verbal Aggression sub-scale of the CTS; das measured by the Violence sub-scale of the CTS

Table 3: Differences in Conflict Resolution Style Pre and Post Dementia $(\mathrm{N}=254)$.

\section{Limitations and Future Research}

This study was limited by the AV_CAD's use of the year period prior to enrollment in the study as its representation of the post dementia period. While the initial AV_CAD attempted to collect data over 4 time periods including, "did it happen in the course of your relationship with the elder/caregiver $\ldots$ 'in the period prior to symptoms?'; 'in the period since diagnosis?'; 'in the past year?' and 'ever?' "; data for the period "in the period since diagnosis" was lost due to computer difficulties with the original lap-top computer programming. As a result, while all persons who participated in the AV_CAD study were required to have a diagnosis of Alzheimer's Disease to eligible for enrollment and thus the period "in the past year" represents conflict resolution strategy used after the onset of dementia (no patient was diagnosed less than a year prior to participating), it is likely that these data are an under-representation of abuse prevalence as persons may exist who use verbal aggression or violence as a strategy in the period since diagnosis, though not in the past year.

Additional under-representation of actual mistreatment prevalence may stem from the fact that this study represents cases of persons collected only in the state of Florida who were willing to participate in this research. As such, it is possible that this study does not represent persons from other states, nor persons who would be unwilling to participate truthfully in a study on violence and aggression in community based $\mathrm{AD}$ families. As such it is likely that persons who are engaging in reciprocal violence are represented in greater numbers in this study than those who are engaging in abuse for more malevolent reasons such as power and control. Many of the persons who admitted verbal or physical mistreatment of their care recipient requested referral to services at the conclusion of their participation in this study, clearly acknowledging this behavior as inappropriate and demonstrating a willingness to change their behavior. It is likely that those who are abusing for malevolent reasons would be more likely to keep their care recipient isolated and less likely to agree to participation in a study such as this.

While this study makes a valuable contribution to the literature in light of the limited information that is known about change in risk for elder mistreatment over time in people with Alzheimer's disease, future research should include a larger geographic region and a more diverse sample. Monitoring change in a prospective study would also aid in the elimination of recall bias. Caregivers were asked to recall periods prior to dementia symptoms and over the past year and as a result their answers are filtered through their recollection of their experiences.

Violence is emerging as a significant clinical challenge in families living with a relative diagnosed with Alzheimer's disease or a related dementia [21,41,42,44-46]. Regardless of the perpetrator, when aggressive and violent behaviors occur, the health and wellbeing of the entire family are at risk.

\section{Conclusion}

This study supports the notion that elder abuse in a large number of persons with Alzheimer's disease may be in part a result of the etiology of the disease and is susceptible to change over time. As the data illustrate there are significant increases in the use of verbal aggression and violent conflict resolution strategies used by both patients and caregivers in the period after diagnosis, when these strategies were not used prior to the onset of dementia symptoms. Secondary symptoms of dementia such as aggression, violence, and combativeness are particularly difficult for caregivers to cope with and manage but may be amenable to treatment resulting in a decrease risk for elder abuse. Although this study was confined to participants residing in the state of Florida, USA, findings from this study have implications for other developed countries that are dealing with the challenges posed by an increasing number of people with dementia and where elder mistreatment is also prevalent.

\section{Competing Interests}

All authors declare they have no competing interests.

\section{Authors Contributions}

Carla VandeWeerd participated in the modification of study design, the collection of study data, data base building, data base management, data analysis and was the lead in drafting the manuscript.

Gregory Paveza participated in the study design, data collection, data analysis and drafting of the manuscript.

Lianne Estefan participated in data analysis and drafting of the manuscript.

Jaime Corvin participated in the data analysis and drafting of the manuscript.

\section{Human Subjects}

This research was conducted under the supervision of the Internal Review Board at the University of South Florida and conforms to IRB standards for the ethical treatment of human subjects. 


\section{References}

1. National Committee on Elder Abuse (1998) The Administration on Aging (DHHS: The National Elder Abuse Incidence Study (Final Report). Washington DC.

2. Humphreys J, Cooper BA, Miaskowski C (2011) Occurrence, characteristics, and impact of chronic pain in formerly abused women. Violence Against Women 17: 1327-1343.

3. Hudson MF (1988) A Delphi studies of elder mistreatment: Theoretical definitions, empirical referents and taxonomy. PhD Thesis. The University of Texas at Austin.

4. Barer BM (1997) The Secret Shame of the Very Old: "I've Never Told This to Anyone Else. J Ment Health Aging 3: 365-375.

5. Fisher BS, Regan SL (2006) The extent and frequency of abuse in the lives of older women and their relationship with health outcomes. Gerontologist 46: 200-209.

6. George LK, Gwyther LP (1986) Caregiver well-being: a multidimensional examination of family caregivers of demented adults. Gerontologist 26: 253-259.

7. Light E, Lebowitz B (1994) Alzheimer's Disease Treatment and Family Stress: Directions For Research. Rockville: National Institute of Mental Health.

8. Saverman B (1994) Formal carers in healthcare and the social services witnessing the abuse of elderly in their homes. Umea: Umea University.

9. Zarit SH, Todd PA, Zarit JM (1986) Subjective burden of husbands and wives as caregivers: a longitudinal study. Gerontologist 26: 260-266.

10. Baker MW, LaCroix AZ, Wu C, Cochrane BB, Wallace R, et al. (2009) Mortality risk associated with physical and verbal abuse in women aged 50 to 79. J Am Geriatr Soc 57: 1799-1809.

11. Lachs MS, Williams CS, O'Brien S, Pillemer KA, Charlson ME (1998) The mortality of elder mistreatment. JAMA 280: 428-432.

12. Comijs HC, Pot AM, Smit JH, Bouter LM, Jonker C (1998) Elder abuse in the community: prevalence and consequences. J Am Geriatr Soc 46: 885-888.

13. Lewis M (1992) Shame: The Exposed Self. New York: The Free Press.

14. Metge J (1986) In and Out of Touch: Whakamaa in cross cultural perspective. Wellington: Victoria University Press.

15. Begle AM, Strachan M, Cisler JM, Amstadter MB, Acierno R (2011) Elder mistreatment and emotional symptoms among older adults in a largely rural population: The South Carolina Elder Mistreatment Study. J Interpers Violence 26: 2321-2332.

16. Fisher BS, Zink T, Regan SL (2011) Abuses against older women: prevalence and health effects. J Interpers Violence 26: 254-268.

17. Luo Y, Waite LJ (2011) Mistreatment and psychological well-being among older adults: exploring the role of psychosocial resources and deficits. J Gerontol B Psychol Sci Soc Sci 66: 217-229.

18. Acierno R, Hernandez MA, Amstadter AB, Resnick HS, Steve K, et al. (2010) Prevalence and correlates of emotional, physical, sexual, and financial abuse and potential neglect in the United States: The National Elder Mistreatment Study. Am J Public Health 100: 292-297.

19. Pillemer K, Finkelhor D (1988) The prevalence of elder abuse: a random sample survey. Gerontologist 28: 51-57.

20. Block M, Sinnott J (1979) The battered elderly syndrome: An exploratory study. College Park: University of Maryland, Center on Aging.

21. Coyne AC, Reichman WE, Berbig LJ (1993) The relationship between dementia and elder abuse. Am J Psychiatry 150: 643-646.

22. Sengstock MC, Hwalek M (1983) Sources of information used in measures for the identification of elder abuse. In proceedings of the Annual Meeting of the Gerontological Society of America.

23. Tatara T (1993) Understanding the nature and scope of domestic elder abuse with the use of state aggregate date: summaries of the key findings of a national survey of state APS and aging agencies. J Elder Abuse Negl 5: 35-57.
24. Bristowe E, Collins J (1989) Family mediated abuse of noninstitutionalized frail elderly men and women living in British Colombia. Journal of Elder Abuse and Neglect 1: 45-64.

25. Anetzberger GJ (1987) The Etiology of Elder Abuse by Adult Offspring. Chicago: Springfield Publishing.

26. Reay AM, Browne KD (2001) Risk factor characteristics in carers who physically abuse or neglect their elderly dependants. Aging Ment Health 5: 56-62.

27. Kosberg J, Garcia J (1995) Common and unique themes on elder abuse from a worldwide perspective. Journal of Elder Abuse and Neglect 6: 183-197.

28. Pillemer K (2004) Elder abuse is caused by the deviance and dependence of abusive caregivers. In current Controversies on Family Violence. Edited by Loseke D, Gelles R, Cavanaugh M Newbury Park: Sage Publications.

29. Wolf RS, Pillemer KA (1997) The Older Battered Woman: Wives and Mothers Compared. Journal of Mental Health and Aging 3: 325-336.

30. Bendik M (1992) Reaching the breaking point: Dangers of the mistreatment in elder caregiving situations. Journal of Elder Abuse and Neglect 4: 39-59.

31. Lachs MS, Pillemer K (2004) Elder abuse. Lancet 364: 1263-1272.

32. Barer BM (1992) The Relationship Between Homebound Older People and Their Home Care Worker. The Journal of Gerontological Social Work 19: 129-147.

33. Anetzberger G, Korbin J, Austin C (1994) Alcoholism and Elder Abuse. J Interpers Violence 9: 184-193.

34. Flaherty A, Raia P (1994) Beyond Risk Protection and Alzheimer's disease. Journal of Elder Abuse and Neglect 6: 75-93.

35. Gallagher D, Wrabetz A, Lovett S, Del Maestro S, Rose J (1990) Depression and other negative effects in family caregivers. In Alzheimer's disease treatment and family stress: Directions for research. Edited by Light \& Lebowitz. New York: Hemisphere 218-244.

36. Haley WE, Levine EG, Brown SL, Berry JW, Hughes GH (1987) Psychological, social, and health consequences of caring for a relative with senile dementia. J Am Geriatr Soc 35: 405-411.

37. Macneil G, Kosberg JI, Durkin DW, Dooley WK, Decoster J, et al. (2010) Caregiver mental health and potentially harmful caregiving behavior: the central role of caregiver anger. Gerontologist 50: 76-86.

38. Vandeweerd C, Paveza GJ (2005) Verbal mistreatment in older adults:a look at persons with Alzheimer's disease and their caregivers in the state of Florida. J Elder Abuse Negl 17: 11-30.

39. Gioglio G, Blakemore P (1982) Elder abuse in New Jersey: The knowledge and Experience of abuse among older New Jerseyans. Trenton: Division on Aging.

40. Cooper C, Blanchard M, Selwood A, Walker Z, Livingston G (2010) Family carers' distress and abusive behaviour: longitudinal study. Br J Psychiatry 196: 480-485.

41. Hamel M, Gold DP, Andres D, Reis M, Dastoor D, et al. (1990) Predictors and consequences of aggressive behavior by community-based dementia patients. Gerontologist 30: 206-211.

42. Paveza GJ, Cohen D, Eisdorfer C, Freels S, Semla T, et al. (1992) Severe family violence and Alzheimer's disease: prevalence and risk factors. Gerontologist 32: 493-497.

43. Hurley AC, Volicer L (2002) Alzheimer Disease: "It's okay, Mama, if you want to go, it's okay". JAMA 288: 2324-2331.

44. Cooney C, Howard R, Lawlor B (2006) Abuse of vulnerable people with dementia by their carers: can we identify those most at risk? Int J Geriatr Psychiatry 21: 564-571.

45. Steinmetz SK (1988) Duty Bound: Elder Abuse and Family Care. Newbury Park: Sage Publications, Vol 166.

46. Cooper C, Selwood A, Blanchard M, Walker Z, Blizard R, et al. (2010) The determinants of family carers' abusive behaviour to people with dementia: results of the CARD study. J Affect Disord 121: 136-142.

47. Strauss MA, Gelles RJ, Steinmetz SK (1980) Behind Closed Doors: Violence in the American Family. New York: Anchor Books. 
Citation: VandeWeerd C, Paveza G, Estefan L, Corvin J (2014) Changes in Conflict Resolution Style over Time: The Risk for Persons with Alzheimer's Dementia. Aging Sci 2: 127. doi:10.4712/2329-8847.1000127

Page 7 of 7

48. Pillemer D (1986) Risk factors in elder abuse: Results from a case contro study. In Elder abuse: conflict in the family. Edited by Pillemer K, Wolf RD, Auburn 239-263.

49. Pillemer K, Finkelhor D (1988) The prevalence of elder abuse: a random sample survey. Gerontologist 28: 51-57.

50. Feil N (1993) The Validation Breakthrough: Simple Techniques for Communicating with People with "Alzheimer's-Type Dementia" Baltimore: Health Professions Press.

51. Bell V, Troxell D (1997) The Best Friends Approach to Alzheimer's Care. Baltimore: Health Professions Press.
52. Toseland RW, Labrecque MS, Goebel ST, Whitney MH (1992) An evaluation of a group program for spouses of frail elderly veterans. Gerontologist 32: 382-390.

53. Coyne A (1991) The relationship between cognitive impairment and elder abuse. In Tatara $\mathrm{T}$ (Ed.) Findings of five elder abuse studies. Washington, DC: National Agency Resource Center on Elder Abuse 23-50. 